\title{
Enzymatic pretreatment and microwave extraction of asiaticoside from Centella asiatica
}

\author{
Cheng-Xiao Wang, Wei Han", Liang Fan, Chun-Li Wang
}

Engineering Center for Traditional Chinese Medicine Modernization, East China University of Science and Technology, Shanghai, China.

E-mail: ${ }^{\text {whan@ecust.edu.cn }}$

Received 3 July 2009; revised 13 July 2009; accepted 19 July 2009.

\begin{abstract}
The extraction of asiaticoside from Centella asiatica by enzymatic pretreatment and microwave extraction (EPME) was studied in this article. The effects of several important factors such as temperature of enzymatic pretreatment, liquid to solid ratio and microwave radiation time were investigated by quadric regression orthogonal design experiment and were analyzed by response surface. An extraction model with well forecast performance was then established. The results indicate that the optimum extraction condition was as follows: liquid to solid ratio was $36 \mathrm{~mL} / \mathrm{g}$, temperature of enzymatic pretreatment was $45^{\circ} \mathrm{C}$, enzymatic time was $30 \mathrm{~min}$, and microwave radiation time was 110s. On such conditions the yield was $27.10 \%$.
\end{abstract}

Keywords: Asiaticoside; Enzymolysis; Microwave Extraction; Centella Asiatica

\section{INTRODUCTION}

Centella asiatica (L.) Urban, a perennial herb belonging to the umbelliferae family, is well known as a traditional Chinese herbal medicine. Its conventional efficacy is clearing away heat and toxic, inducing diuresis and reducing edema. The major active constituents of Centella asiatica are asiaticoside and madecassoside. It has been used for the treatment of hot and humid jaundice, traumatic injuries, infectious hepatitis and dermatosis [1]. Currently, some conventional extraction methods are mostly adopted for the extraction of asiaticoside $[2,3,4]$, such as aqueous extraction and ethanol extraction.

In recent years, new kinds of extraction techniques appeared, including enzymolysis and microwave extraction. The former has impressive effects with characteristics of high catalytic efficiency, high specificity, mild reactive conditions and preserving the original efficacy of active compounds to the maximum [5]. The later method has many advantages, such as shorter time, less solvent, higher extraction rate and better products with lower cost $[6,7]$. However, the application of the combination of these two methods on plant materials was rarely reported.

For the purpose of improving the efficient of asiaticoside extraction, reducing the cost, the EPME method is employed in this article, quadric regression orthogonal design is adopted to investigate the effects of three main extraction parameters including temperature of enzymatic pretreatment, liquid to solid ratio and microwave radiation time on the yield of asiaticoside, and optimum extraction process is worked out.

\section{MATERIALS AND METHODS}

\subsection{Equipments and Reagents}

An ER-692 microwave oven (as shown in Figure 1) with a power output of $650 \mathrm{~W}$, operating at $2450 \mathrm{MHz}$, was mechanically modified to fit a reflux system that enables extraction performed under atmospheric settings and permits solvent containment. The extraction vessel was a $250-\mathrm{mL}$ three-necked round-bottomed flask connected to a water condenser.

Thermostat with magnetic stirrer (Model DF-101S, Yuhua Experimental Apparatus Co., Shanghai) was used as enzymolysis device. UV spectrophotometer (Model 1900PC, Yayan Electronic Co., Shanghai) was used for determination.

Dry Centella asiatica (fitted for the Chinese Pharmacopoeia); Asiaticoside standard (Provided by National Institute for the Control of Pharmaceutical and Biological Products, Beijing); Cellulase ( $\geq 400 \mathrm{U} / \mathrm{mg}$ ); Anhydrous ethanol and concentrated sulfuric acid used in the experiment were all of analytical grade.

\subsection{Analytic Method of Asiaticoside}

The concentration of the asiaticoside in this process was determined by ultraviolet spectrophotometry [8] and the result was expressed as extraction yield, i.e. unit extrac- 
tion quantity (g asiaticoside/g Centella asiatica).

The asiaticoside standard sample solution (was diluted by anhydrous ethanol) and extraction solution were scan ed at 200-400nm respectively, there were the same absorption peak at $277 \mathrm{~nm}$ (Figure 2), which was close to the literature values [9]. So $277 \mathrm{~nm}$ was chosen for the UV wavelengths.

The asiaticoside standard sample solution (concentration: $92 \mu \mathrm{g} / \mathrm{mL}$ ) was precisely measured at $0.0,0.5,1.0$, $1.5,2.0,2.5 \mathrm{~mL}$, and put into a $10 \mathrm{~mL}$ volumetric flask. Firstly, volatilized out the solvent ethanol in the boiling water bath, and then added the $2 \mathrm{~mL}$ concentrated sulfuric acid $\left(\mathrm{H}_{2} \mathrm{SO}_{4}\right)$ after the flask cooling to the ambient temperature, heated for $30 \mathrm{~min}$ in $80^{\circ} \mathrm{C}$ water bath. Finally, added anhydrous ethanol to the scale after the flask getting to the ambient temperature. According to the ultraviolet spectrophotometry, the prepared solution was measured at $277 \mathrm{~nm}$. Regression equation and correlation coefficient were $y=43.40 x-2.49$ and $r=0.9992(n=7)$ respectively. The linear range was $4.6 \sim 23.0 \mu \mathrm{g} / \mathrm{mL}$.

The $0.5 \mathrm{~mL}$ test sample solution was accurately measured and placed into a $10 \mathrm{~mL}$ volumetric flask, following the preparation method of regression equation. The absorbance of test sample was determined, and the yield of asiaticoside in the test sample was calculated in accordance with the following equation:

Yield of asiaticoside $(\%, w / w)=$

$$
\frac{(43.40 \mathrm{~A}-2.49) \mathrm{Vn}}{3 \times 10^{6}} \times 100 \%
$$

where, A, the absorbance of asiaticoside in test sample; $\mathrm{V}$, volume of solvent, $\mathrm{mL}$; $\mathrm{n}$, diluted times.

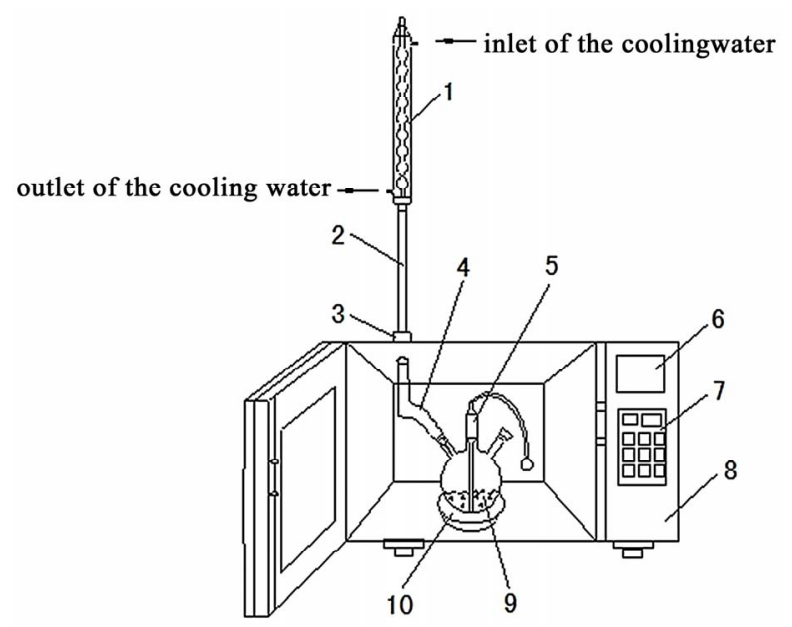

Figure 1. Microwave equipment diagram; 1-Water condenser; 2-Air condenser; 3-Copper tube; 4-Tailored tube; 5-Air agitator; 6-Status display; 7-Microwave oven timer; 8-Microwave oven; 9-Flask; 10-Base of flask.

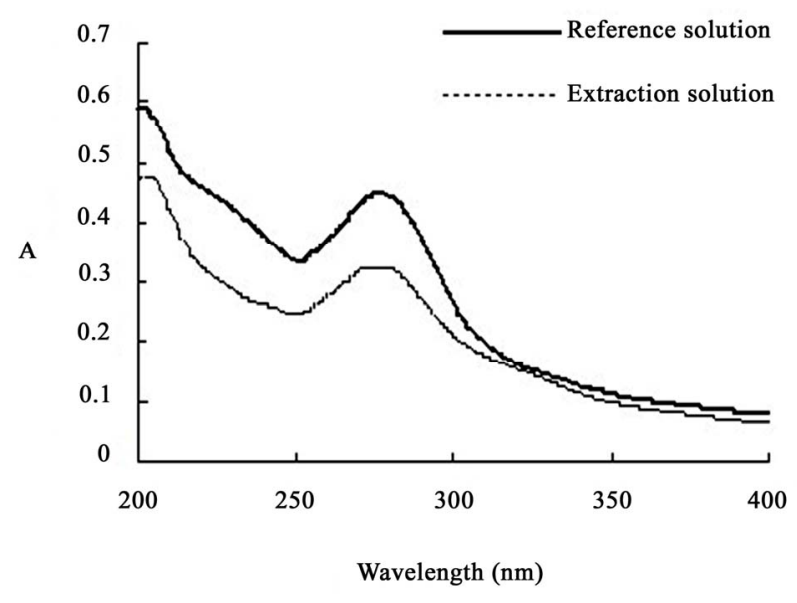

Figure 2. UV spectra of reference solution and extraction solution.

\subsection{Enzymatic Pretreatment and Microwave Extraction}

The dry Centella asiatica (sieved through 10 screen mesh) $3.0 \mathrm{~g}$ was accurately weighed and placed into a threeneck flask with 3\% cellulase solution (dissolved by deionized water), then the deionized water as solvent was added in according to a certain ratio $(\mathrm{mL} / \mathrm{g})$ of material to solvent volume, and the mass of system was weighed.

Three-neck flask was put into the thermostat with magnetic stirrer, setting enzymolysis time at 30min according to the pre-experiment, while the temperature of enzymatic reaction and stirring speed were set at certain values. Then the flask was taken out and placed into the microwave oven immediately. The radiation exposure was 30s for preventing the serious evaporation of solvent. At the end of each exposure, the system was brought back to ambient temperature during 2 3 min interval by cooling it with a water bath. An extraction cycle was defined as the combination of phases of radiation and phases without radiation in which the solvent cooled. The sum of radiation exposure of processing extraction cycles served as the overall intensity of microwave radiation. The extraction solution was agitated with an air pump to promote heat uniformity while exposing to microwave radiation. After the radiation, the flask was taken out to weigh the total mass again, and the lost weight was supplemented. The extract was filtered through $0.45 \mu \mathrm{m}$ millipore filter, and then abandoned the initial filtrate, added $0.5 \mathrm{~mL}$ subsequent filtrate to a $10 \mathrm{~mL}$ volumetric flask with anhydrous ethanol as the test sample.

\section{RESULTS AND DISCUSSIONS}

\subsection{Effect of Temperature of Enzymatic Pretreatment on EPME}

As shown in Figure 3, the results indicate that the yield of asiaticoside was increased with the increase of temperature of enzymatic pretreatment, reached a high point 
at $45^{\circ} \mathrm{C}$. Because the temperature of enzymatic pretreatment was a significant factor in the process of enzymolysis, it affected the enzyme activity as well as the rates of enzyme-catalyzed reactions. When the temperature was lower than $45^{\circ} \mathrm{C}$, the increase of temperature can improve the cellulase activity, accelerate the degradation of cytoderm. While the temperature of enzymatic pretreatment was higher than $45^{\circ} \mathrm{C}$, the cellulase activity was decreased, leading to the reduction of the yield. Therefore the temperature of enzymatic pretreatment for $45^{\circ} \mathrm{C}$ was used.

\subsection{Effect of Liquid to Solid Ratio on EPME}

As it is known, the liquid to solid ratio is very important in the extraction. From the perspective of mass transfer, it mainly affects the concentration gradient between liquid phase and solid phase. Figure 4 shows that the yield of asiaticoside was increased with the increase of liquid to solid ratio. After the peak, the yield of asiaticoside was decreased with the increase of liquid to solid ratio. The higher liquid to solid ratio, the longer time for the solution elevated to the same temperature was required. At the same microwave radiation, the temperature of the system with larger amount of solvent was relatively lower; the solute diffusion would be affected. So the ratio for $30 \mathrm{~mL} / \mathrm{g}$ was chosen.

\subsection{Effect of Microwave Radiation Time on EPME}

Figure 5 described that the extraction yield sharply increased before $60 \mathrm{~s}$ and was asymptotic to a steady value during $60 \sim 120 \mathrm{~s}$, then falls down after $120 \mathrm{~s}$. At the preliminary stage of extraction, the velocity of molecular thermal motion quickened and the asiaticoside was quickly separated from the cell into solution. The extraction process had tended towards equilibrium since $60 \mathrm{~s}$. When

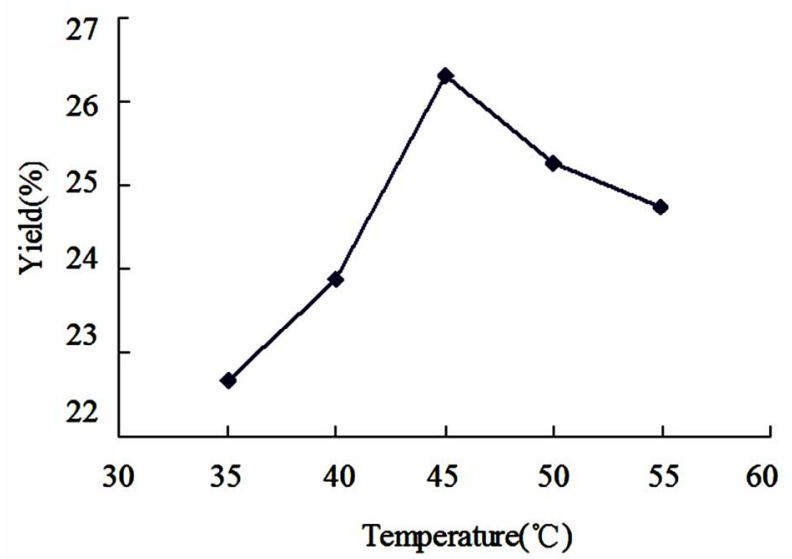

Figure 3. Effect of temperature of enzymatic pretreatment on EPME.

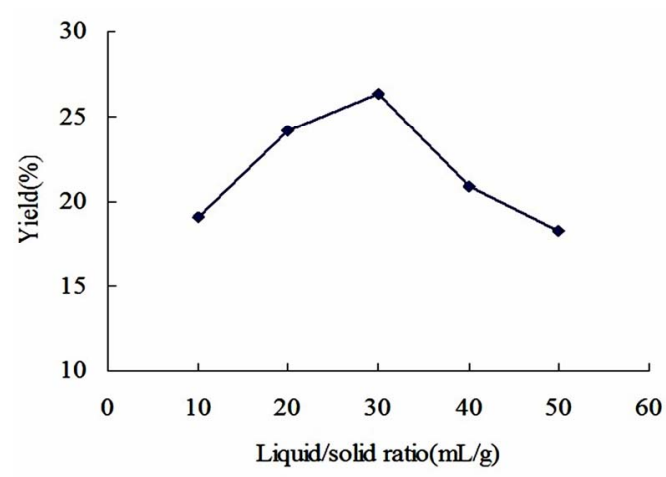

Figure 4. Effect of liquid to solid ratio on EPME.

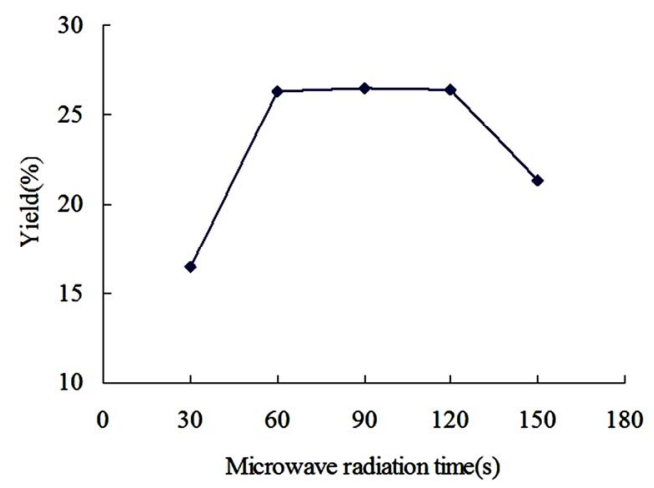

Figure 5. Effect of microwave radiation time on EPME.

the microwave radiation time exceeded 120s, the system was hyperthermal, the vaporization reflux of solution increased. All of above brought about the reduction of effective contact interval of solvent and plants, and caused the decrease of the thermal effects. In addition, the extension of microwave radiation time would increase the consumption of energy. Thus the microwave radiation time for $60 \mathrm{~s}$ was used in the experiment.

\subsection{Quadratic Regression Orthogonal Design Results}

The quadratic regression orthogonal design was employed to evaluate the relevance of the three main extraction factors including enzymatic temperature, liquid to solid ratio and the microwave radiation time, while other factors including grinding degree of plant material, concentration of enzyme, enzymatic pretreatment time and $\mathrm{pH}$ of the solvent were constant according to the pre-experiments. The multivariate study allows the identification of interactions between variables and provides a complex exploration of the experimental domain to be studied with a number of experiments optimized.

The three key variables studied were pointed at five separate coded levels [11], $-1,0,+1,+\gamma(=1.682)$ and their values were selected on the basis of previous experiments. The natural values and coded levels used in this multivariate study are presented in Table 1. 
Table 1. Factors of orthogonal experiment.

\begin{tabular}{cccc}
\hline & $\mathbf{X}_{1}$-Microwave & $\mathbf{X}_{\mathbf{2}}$-Liquid to & $\mathbf{X}_{\mathbf{3}}$-Enzymatic \\
\hline$-\gamma$ & 9 & 13 & 28 \\
-1 & 30 & 20 & 35 \\
0 & 60 & 30 & 45 \\
1 & 90 & 40 & 55 \\
$\gamma$ & 111 & 47 & 62 \\
$\Delta$ & 30 & 10 & 10 \\
\hline
\end{tabular}

The statistical analysis software was applied in this experiment to establish a regression Eq.2, in this equation, the terms of $\mathrm{Y}, \mathrm{X}_{1}, \mathrm{X}_{2}$, and $\mathrm{X}_{3}$ respectively represent the yield of asiaticoside, microwave radiation time, liquid to solid ratio and enzymatic temperature:

$$
\begin{aligned}
\mathrm{Y}= & 25.8963+1.8150 \mathrm{X}_{1}-0.7646 \mathrm{X}_{2}+0.3464 \mathrm{X}_{3} \\
& +0.9363 \mathrm{X}_{1} \mathrm{X}_{2}+0.4688 \mathrm{X}_{1} \mathrm{X}_{3}+0.1363 \mathrm{X}_{2} \mathrm{X}_{3} \\
& -0.7065 \mathrm{X}_{1}{ }^{2}-0.6852 \mathrm{X}_{2}{ }^{2}-1.7547 \mathrm{X}_{3}{ }^{2}
\end{aligned}
$$

Analysis of variance was carried out in order to test the signification of the regression model. Thus, various statistical data such as sum of squares (SS), mean squares (MS), F-ratio were given in Table 2.

The F-ratio in Table 2 was the ratio of the meansquared error to the pure error obtained from the replicates at the design center. The significance of the F-ratio depends on the number of degrees of freedom (d. f.) in the model. Thus, the effects lower than 0.05 in this column were significant.

As shown in Table 2, $F_{\text {Regression }}=10.866>F_{0.05}(9$, $8)=3.388$, the regression of (2) was significant, while $\mathrm{F}_{\text {Lack of fit }}=3.478<\mathrm{F}_{0.05}(5,8)=3.687$, the lack of fit was non-significant. Therefore, (2) had well predictivity under the experimental condition. In the test of regression coefficient, F-ratio for terms $\mathrm{X}_{3}, \mathrm{X}_{1} \mathrm{X}_{3}, \mathrm{X}_{2} \mathrm{X}_{3}$ (1.253, $1.344,0.114)$ were lower than $F_{0.05}(1,8)=5.318$, so these terms were not significant. On the contrary, the F-ratio for other terms $\left(\mathrm{X}_{1}, \mathrm{X}_{2}, \mathrm{X}_{1} \mathrm{X}_{2}, \mathrm{X}_{1}{ }^{2}, \mathrm{X}_{2}{ }^{2}\right.$ and $\left.\mathrm{X}_{3}{ }^{2}\right)$ which were higher than $\mathrm{F}_{0.05}$, indicated the significance of these terms. As the orthogonality of this experiment, the insignificant terms were cut out to simplify the (3):

$$
\begin{aligned}
\mathrm{Y}= & 25.8963+1.8150 \mathrm{X}_{1}-0.7646 \mathrm{X}_{2}+0.9363 \mathrm{X}_{1} \mathrm{X}_{2} \\
& -0.7065 \mathrm{X}_{1}^{2}-0.6852 \mathrm{X}_{2}{ }^{2}-1.7547 \mathrm{X}_{3}{ }^{2}
\end{aligned}
$$

Table 2. Variance analysis of test results.

\begin{tabular}{llllll}
\hline Source & d.f. & SS & MS & F & $\mathbf{F}_{\mathbf{0 . 0 5}}$ \\
\hline $\mathrm{X}_{1}$ & 1 & 44.995 & 44.995 & 34.409 & 5.318 \\
$\mathrm{X}_{2}$ & 1 & 7.985 & 7.985 & 6.106 & \\
$\mathrm{X}_{3}$ & 1 & 1.639 & 1.639 & 1.253 & \\
$\mathrm{X}_{1} \mathrm{X}_{2}$ & 1 & 7.012 & 7.012 & 5.363 & \\
$\mathrm{X}_{1} \mathrm{X}_{3}$ & 1 & 1.758 & 1.758 & 1.344 & \\
$\mathrm{X}_{2} \mathrm{X}_{3}$ & 1 & 0.148 & 0.148 & 0.114 & \\
$\mathrm{X}_{1}{ }^{2}$ & 1 & 7.935 & 7.935 & 6.068 & \\
$\mathrm{X}_{2}{ }^{2}$ & 1 & 7.463 & 7.463 & 5.707 & \\
$\mathrm{X}_{3}{ }^{2}$ & 1 & 48.949 & 48.949 & 37.432 & \\
Regression & 9 & 127.885 & 14.209 & 10.866 & 3.388 \\
Lack of fit & 5 & 22.740 & 4.548 & 3.478 & 3.687 \\
Pure error & 8 & 10.461 & 1.308 & & \\
Total & 22 & 161.087 & 7.322 & & \\
\hline
\end{tabular}

Eq.3 indicated that the microwave radiation time and liquid to solid ratio were the main factors that influence the yield because of the significance of the terms $\mathrm{X}_{1}$ and $\mathrm{X}_{2}$. The significance of $\mathrm{X}_{1} \mathrm{X}_{2}$ suggested the obvious interaction between microwave radiation time and liquid to solid ratio. And the significance of all the quadratic terms demonstrated the nonlinear relationship between the three factors and the yield of extraction.

\subsection{Analysis of Response Surface}

The 3D surface curves were drawn to illustrate the main and interactive effects of the three factors on the yield. The response surfaces are shown in Figures 6,7,8 with one variable kept at optimum level and the other two varied within the experimental range.

Figure 6 shows the effect of liquid to solid ratio(X2) and extraction time(X1) on the yield. A quadratic effect for both factors on the response can be observed. At a low level of X2 $(-2)$, the system was readily hyperthermal and vaporization of the solvent could reduced the yield with the increasing of microwave time. And at a high level of X2 (2), the yield displayed an increasing curve in the experimental range of X1. It is due to the distinctly interaction between $\mathrm{X} 1$ and $\mathrm{X} 2$, which was implied in the Eq.3. The maximum yield was predicted when $\mathrm{X} 1$ was in the range of 1.5 to 1.7 and $\mathrm{X} 2$ varied from 0.4 to 0.6 .

Figure 7 depicts the effect of enzymatic temperature(X3) and extraction time(X1), as both them exerting a quadratic effect. As shown in the Figure 7, an increase in yield resulted when X3 was increased in the level range from -2 to 0 , then the curve started to go down, which may indicate that a level of X1 at approximate 0 is required to achieve maximum yield. Likewise, an increase in yield resulted when X1 was increased in the code range from -2 to 1.5 , and then the yield was slightly reduced. In the response surface, X1 exerted a more significant effect on yield than $\mathrm{X} 3$, and no obvious interaction between X1 and X3 was observed, which was well in agreement with Eq.3.

In Figure 8, yield showed quadratic curve depending upon the liquid to solid ratio(X2), whereas no significant effect was observed in the enzymatic temperature(X3). Because the ratio was a key factor which influences the impetus in mass transfer of both enzymatic pretreatment and microwave extraction processes, it exerted a more significant effect on yield than the factor of enzymatic temperature. According to the response surface, there was no obviously interaction between $\mathrm{X} 2$ and $\mathrm{X} 3$, and it was also supported by the Eq.3.

\subsection{Optimization of EPME Condition}

Yield of extraction was employed as the evaluation objective in the optimization of the parameter to ensure it reaches the peak under constraint conditions. According 


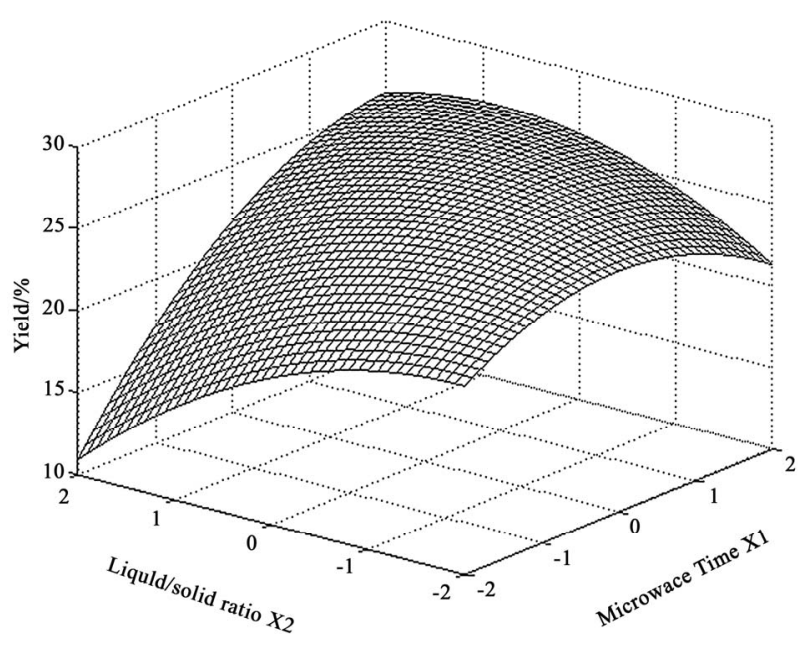

Figure 6. Response surface graph of microwave radiation time and liquid/solid ratio.

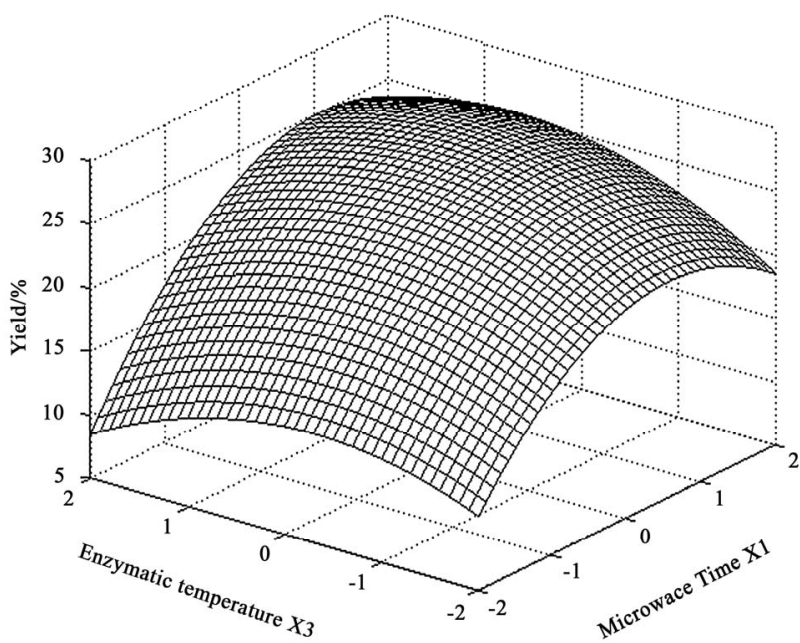

Figure 7. Response surface graph of microwave radiation time and enzymatic temperature.

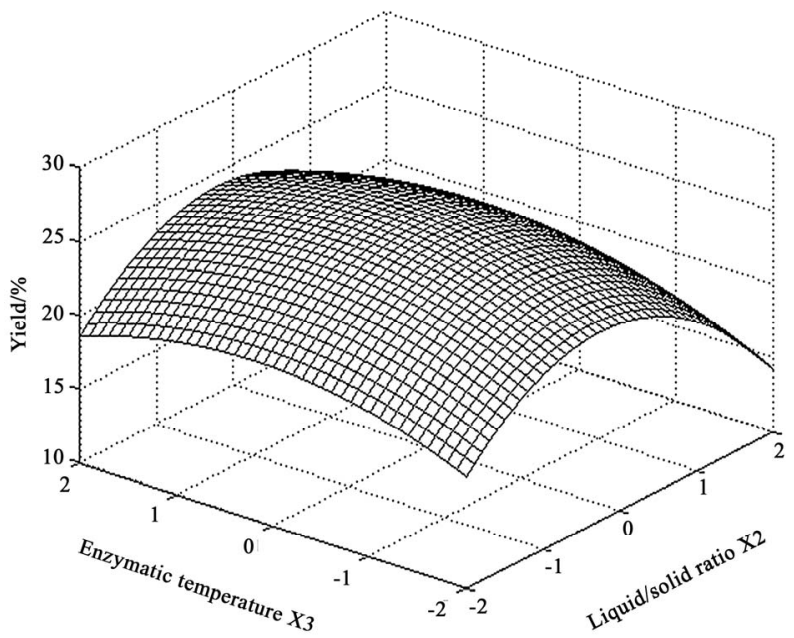

Figure 8. Response surface graph of liquid/solid ratio and enzymatic temperature.
Table 3. Optimum values and verification results

\begin{tabular}{ccccc}
\hline & \multirow{2}{*}{$\begin{array}{c}\text { Coded } \\
\text { Value }\end{array}$} & $\begin{array}{c}\text { Calculated } \\
\text { Value }\end{array}$ & & \multicolumn{2}{c}{ Yield/\% } \\
\cline { 4 - 5 } & & & $\begin{array}{c}\text { Esti- } \\
\text { mated } \\
\text { Value }\end{array}$ & $\begin{array}{c}\text { Measured } \\
\text { Value }\end{array}$ \\
\hline $\mathrm{X}_{1}(\mathrm{~s})$ & 1.672 & 110 & & \\
$\mathrm{X}_{2}(\mathrm{~mL} / \mathrm{g})$ & 0.584 & 36 & 27.19 & 27.10 \\
$\mathrm{X}_{3}\left({ }^{\circ} \mathrm{C}\right)$ & 0 & 45 & & \\
\hline
\end{tabular}

to (3), model was then built up as described hereinafter [10]:

Objective function: $\mathrm{Y}\left(\mathrm{X}_{1}, \mathrm{X}_{2}, \mathrm{X}_{3}\right)$;

Constraint conditions: $-1.682 \leq \mathrm{X}_{\mathrm{i}} \leq 1.682 ;(\mathrm{i}=1,2,3)$

The optimum parameters and maximal yield were worked out by Newton's iteration method. The results were shown in Table 3. To compare the predicted result $(82.10 \%)$ with the practical value, the rechecking experiment was performed using this deduced optimal condition. The mean value of $27.10 \%(\mathrm{n}=3)$, obtained from real experiments, demonstrated the validity of the model, since there was no significant differences between $27.19 \%$ and $27.10 \%$. The strong correlation between the real and the predicted results confirmed that the extraction model was adequate to reflect the expected optimization.

\section{CONCLUSIONS}

The quadratic regression orthogonal design was used in this research, an extraction model which can accurately predict the yield of asiaticoside extraction under the experimental condition was established.

Through the analysis of experiment data, it can be found that the microwave radiation time and liquid to solid ratio significantly influence the yield of the extraction. Especially, there was an obvious interaction between the microwave radiation time and liquid to solid ratio.

The optimum combination of the parameters for the extraction of asiaticoside was obtained by the mathematical methology; it was microwave radiation time for $110 \mathrm{~s}$; liquid to solid ratio for $36 \mathrm{~mL} / \mathrm{g}$, and enzymatic pretreatment temperature for $45^{\circ} \mathrm{C}$. On this condition, the maximum yield of extraction was $27.10 \%$, closed to the estimated value $27.19 \%$.

The EPME procedure had the advantages of less time, high efficiency of extraction, and environmentally friendly. It can be applied to other extraction of plant materials. But the expansive cost of the enzyme and difficulty in industrialization of microwave extraction would limit the further application of EPME.

\section{ACKNOWLEDGMENTS}

The work was supported by National Natural Science Foundation of China (No. 20006003). 


\section{REFERENCES}

[1] Randriamampionona, D., Diallo, B., and Rakotoniriana, F., (2007) Comparative analysis of active constituents in Centella asiatica samples from Madagascar: Application for ex situ conservation and clonal propagation, Fitoterapia, 78, 482-489.

[2] Verma, K., Bhartariya, G., and Gupta, M., (1999) Reversephase high performance liquid chromatography of asiaticoside in Centella asiatica, Phytochem. Anal., 10, 191-193.

[3] Sarma, K., Khosa, L., and Chansauria, N., (1995) Antistress activity of Tinospora cordfolia and Centella asiatica extracts, Phytother. Res., 10, 181-183.

[4] Flora, S. and Gupta, R., (2007) Beneficial effects of Centella asiatica aqueous extract against arsenic-induced oxidative stress and essential metal status in rats, Phytother. Res., 21, 980-988.

[5] Li, B. B., Smith, B., and Hossain, M., (2006) Extraction of phenolics from citrus peels II, Enzyme-assisted extraction method, Sep. Purif. Technol., 48, 189-196.
[6] Bayramoglu, B., Sahin, S., and Sumnu, G., (2008) Solventfree microwave extraction of essential oil from oregano, J. Food Eng., 88, 535-540.

[7] Proestos, C. and Komaitis, M., (2008) Application of microwave-assisted extraction to the fast extraction of plant phenolic compounds, Food Sci. Technol-LEB, 41, 652-659.

[8] Pan, X. J., Niu, G. G., and Liu, H. Z., (2003) Microwave-assisted extraction of tea polyphenols and tea caffeine from green tea leaves, Chem. Eng. Process, 42, 129133.

[9] Lu, X. Y., "Determination of asiaticosides by UV- spectrophotography. (2005) J Modern Food Drug, 16, 15-16.

[10] Ma, S. F., Wang, L. Q., and Hu, Z. C., (2005) Enzymatic extraction of the submerged mycelium polysaccharide from Pleurotus nebrodensis, T CSAE, 22, 198-201.

[11] Virot, M., Tomao, V., and Colnagui, G., (2007) New microwave-integrated Soxhlet extraction an advantageous tool for the extraction of lipids from food products, J. Chromatogr. A, 1174, 138-144. 